is not entirely satisfactory. . . The modern affinities of the nunerous leaves of the higher types of dicotyledonous trees found in it, present a strong objection to the adoption of the conclusion that it may belong to a lower borizon than the Upper Greensand of British geologists; while its position directly below beds almost beyond doubt representing the Lower or Gray Chalk, precludes its reference to any higher stratigraphical position. Consequently, we have long regarded it as most probably representing in part, if not the whole, the Upper Greensand. . ." As the fossils above mentioned belong to the Museum of Comparative Zoology, I hope to be able to give more detailed information upon these galls and mines.

Cambridge, Mass., January 3

H. A. HAGEN

\section{On Combining Colour-Disks}

THE paper of Lord Rayleigh in NATURE (vol. xxv. p. 64) describing experiments on colour, gives near the close a method of observing the image of colour-disks seen through an inverting prism in rapid rotation, while the disks were at rest. This recalls to mind a method somewhat similar that I bave tried, that will sometimes be found convenient as well as simple: Here the image of the stationary disks is formed in a plane mirror slightly inclined to the axis around which it rotates; by properly proportioning the angle of inclination, the distances from the mirror to the eye and disks, and the sizes of the mirror and disk, it is obvious that a good combination of the colours may be effected, while the adjustment of colours is easily effected with. out stopping the rotation. If, as with my instrument, the clockwork is not heavy enough to give easily the desired speed when the disks are mounted on it, a much higher speed can be obtained with the light mirror: indeed, the mirror might be attached to the end of a wire resting on two supports, and rotated by unwinding a string, and thus colour combinations could be simply effected, and with cheap apparatus. Of course here, as with the inverting prism, the line of vision is inconveniently limited; but with both methods the uncertainty arising from unequal illumination of different parts of the disk may be detected by giving to the disk a slow rotation on its own plane.

University of Michigan, Ann Arbor, U.S.A. Charles K. WEAD December 3r, I88

\section{Sound-Producing Ants}

WITH reference to the question whether ants produce sounds which are of such a pitch as to be inaudible to the human ear, I should like to make a suggestion which occurs to me, but which I have no means of carrying out practically. It is a wellknown acoustical fact that two notes of high pitch sounding together produce a third whose vibrational number is the difference of the vibrational riumbers of the two primary notes. If now we suppose a vibration at the rate of (say) 60,000 per second, another at the rate of 38,000 per second would give a difference note of 22,000 per second, which would be well within the range of audibility. If then we send up a note beyond the extreme limit of audibility, we shall be able to detect the presence of vibrations which exceed that of the note sent up by the highest number of vibrations of audible sound. It would be interesting to know if this has been attempted, and if the microphone can be applied to assist in the investigations.

Hirwain, Aberdare, Jamuary 10

D. M. LEWIS

\section{Nepotism?}

Please, Mr. Editor, is a pet baboon (Nature, vol. xxv. p. 2I7) more interesting than either a pet sparrow or a pet canary bird ? Don't give rise to the suspicion that there is any nepotism in the affair !

Zeist, January ro

INDIAN FossiLs.-Mr. J. W. Oliver informs us that at the Birmingham and Midland Institute there is a small collection of Siwalik fossils which, he understands, were sent some years ago from the British Muceum. Prof. Prestwich writes that there is a very large and fine collection in the Oxford University Museum, presented by Dr. Falconer and Sir Proby Cantling. Prof. Prestwich will be happy to give Mr. Lydekker every facility for the examination of the specimens.

\section{COMPRESSED AIR UPON TRAMWAYS}

$\mathrm{F} E W$ persons unconnected with the practical working of the companies are aware of the great amount of time, labour, and money which have been devoted to the substitution of mechanical for horse-power upon tramways both in this country and abroad. The principal incentive to this exertion has been the large margin of saving which has presented itself in the light of a premium to inventors and capitalists. Motives of humanity towards the horses have also had considerable influence, especially with Parliament, and have contributed in no small degree to the legislative sanctions which have been obtained not only by particular companies, but by the tramway interest in general. In no case however that the writer is aware of, have the tramway companies themselves made any material contributions towards the solution of the problems involved. When the story of the subject comes to be written it will be found full of arguments in favour of the principle that the monopoly granted to inventors by the patent laws is nothing more than a clumsy method of spurring them to exertion, and of providing a remuneration for success which never covers the aggregate losses of failure by which the whole community have been indirectly berefited.

The fact of the horse-tramway companies having refused to assist inventors with money is fully accounted for and rendered excusable not only because they have no funds placed at their disposal by their articles of association for such a purpose, but also because the investment would have been far too speculative to have been sanctioned by the shareholders. Where the companies appear to the writer to have been at fault is that while the margin of saving as between a successful invention and horse-traction is admitted to be enormous, because the invention could hardly be said to be successful unless the margin was a large one, they have never admitted either individually or collectively that some substantial share of the saving should be the reward of the successful inventor. The writer has no hesitation in saying that if the leading companies had put the issue clearly before the inventive capacity of the engineering profession in the shape of an offer of say 30 per cent. of the actual saving in the shape of royalty to the inventor that the problem would have been solved at least six years ago. The farstretching results of such a revolution, even within the comparatively confined area of the tramway interest, would be incalculable. Not to speak of the emancipation of the horses, the employment of capital in channels so consistent with the spirit of the age and the genius of the country as the manufacture of machinery would have economic results affecting the welfare of whole classes of the community, and the impetus given to the intramural locomotion of our large cities would go far to overcome the pressure of difficulties affecting the housing of the poor, which contribute more to the unrest of the people and the propagation of socialistic ideas than the wealthier classes are aware of. The policy of the tramway companies, however, appears to have assumed the character of a fixed determination to give nothing in return for the advantages which would accrue to them from the adoption of a successful mechanical substitute for horses. So long as they maintain this attitude the problem is likely to remain unsolved. Licensees of inventors have followed their example, and at least one case is known to the writer in which a gross breach of agreement has debarred the adoption of an invention which is notoriously efficient. Time no doubt will expose the guilty parties, and their names, instead of being honourably associated with the advance and improvement of mechanical science, will be handed down to posterity with the contempt which they deserve.

A description and illustration have already been given in these pages of a system of tramway traction by means of electricity, and this is no doubt safe in the hands of 